\title{
Canadian tobacco package warning system
}

\author{
Garfield Mahood
}

Major advances in tobacco package warning systems have now been enacted in Canada, Australia, ${ }^{1}$ Singapore and Thailand. The Canadian warnings (September 1994) illustrated on the front cover ${ }^{\star}$ beat the major Aussie reforms (January 1995) to store shelves by only a few months. The warning systems in all of these countries will encourage reforms in tobacco markets worldwide.

Canada's tobacco warnings, which set world precedents $^{2,3}$ (see cover photograph), now appear on all tobacco packages manufactured in Canada or imported from abroad. The fouryear fight for the enactment of the warnings was a frustrating, grinding affair. In the final analysis, the aggressiveness and determination of a handful of Canadian health organisations may bring significant rewards for public health. This essay will explain both the innovations in the Canadian warning system and the improvements that were rejected or missed. The second part of the essay will reveal what it took to ensure that these warnings became law in the face of industry opposition.

\section{Precedents in the Canadian warnings}

The new warnings, eight in all, are required by way of regulation under Canada's Tobacco Products Control Act passed in $1988 .{ }^{4}$ These warnings set precedents in several respects. They are the largest health messages on cigarette packages in the world. The area framing the message occupies $25 \%$ of the face. When the required black or white border is included, the total area of the warning increases to $35 \%$ to $45 \%$ of each of the major surfaces of the package. ${ }^{3}$ The warning is in English on one face and French on the other, thereby satisfying Canada's dual official language requirements.

These warnings, followed closely by the Australian warnings, are the first in the world to be moved to the top of the package. Chris Yaneff, a package designer, described the placement at the top of the package as "a coup" for public health (oral communication from Chris Yaneff, President, Chris Yaneff Ltd, Toronto, Canada, 16 January 1995).

For the first time, the manufacturers have been prevented from hiding warnings in brand colours and graphics and have been forced into a black and white format. Half of the time, the warnings require black text on a white background surrounded by a $3 \mathrm{~mm}$ black border.

\footnotetext{
^ Cover photograph by Shane G Mahood.
}

The remaining time, the typeface is white on a black background enclosed by a $3 \mathrm{~mm}$ white rule. + Early anecdotal reports suggest that the predominantly black warning has greater impact.

The rotating warnings break new ground in content as well as location and format. The Federal Government enacted the first addiction warning in a Western tobacco market ("Cigarettes are addictive") and the strongest warnings about environmental tobacco smoke or ETS ("Tobacco smoke causes fatal lung disease in non-smokers" and "Tobacco smoke can harm your children"). Note that the first ETS message acknowledges a causal relationship between ETS and fatal disease in nonsmokers. These messages are particularly troublesome for the industry. Tobacco manufacturers are still working hard to confuse legislators, the media, and the public about tobacco addiction and the risks of ETS. ${ }^{5}$

Some of the language changes in the Canadian warnings are more subtle but nonetheless significant. Four of the eight new messages move away from the "blame the victim" approach to tobacco control. They shift the responsibility for the risk away from the smoker's behaviour and individual responsibility (for example, "Smoking causes cancer") toward the inherent defects in the product (Cigarettes cause cancer" or "Cigarettes cause fatal lung disease").

Personalisation of messages is a desired attribute of a warning system. The Federal Government was persuaded to personalise three of the messages (such as "Smoking can kill you") but it failed to make personalisation more effective through emphasis (for example, "Smoking can kill you").

\section{Attribution}

The Canadian warnings are strengthened in part by what does not appear in the messages. The warnings are not attributed to any authority, a practice that is believed to weaken the risk message. Current examples of attribution include the introduction to the US warning,

tThe variation in the total size of the warnings from $35 \%$ to $45 \%$ is due to the manufacturers keeping the black or white border at the $3 \mathrm{~mm}$ minimum required in the regulations. Thus the rule and the message may occupy up to $45 \%$ of a small package. As package size increases but the width of the border remains unchanged, the total area of the warning decreases as a percentage of the size of the major face. 
"SURGEON GENERAL'S WARNING: Quitting Smoking Now Greatly Reduces Serious Risks to Your Health" or the European Union Council Directive (89/622/EEC) which leaves any attribution to the discretion of the member states. ${ }^{6}$

\section{Toxic constituents panel}

One side panel of each Canadian package raises the issue of toxic ingredients in cigarette smoke. This panel also departs from the package colours, the toxic contents being listed in black text on a white background. Moreover, the manufacturers must now spell out the purpose of the side panel; the heading "Toxic constituents" must appear. Abbreviations are no longer acceptable. "CO"must now be listed as carbon monoxide and "nic" becomes nicotine.

\section{Carton warning}

Canadian cartons carry one large warning similar in format to the individual package warnings but it must appear on all six surfaces of the carton. This warning requires black typeface on a white background. The message reads "Cigarettes are addictive and cause lung cancer, emphysema and heart disease." The carton warning is $25 \%$ of each of the surfaces. Again, the minimum $3 \mathrm{~mm}$ black rule increases the size of the carton warning to between $33 \%$ and $40 \%$ of each surface.

\section{"De-marketing" the product}

Other benefits, which are not spelled out in the regulation, flow from these reforms, yet they are obvious to the eye. Firstly, the most effective warning of all is simply the act of forcing dramatic changes in the content, location, and graphics of the warnings. For the first time, the Government is requiring warnings that approach being commensurate with the magnitude of the risk of the product in the package.

Second, the package itself is the core of the tobacco marketing process. The manufacturers understand this and spend millions of dollars on package research, design, and promotion. All tobacco advertising, sponsorship, and promotion relates back to the package colours and graphics.

By moving to a black and white warning format, the warning systems of Canada, Australia, Thailand and Singapore begin to strip the tobacco package of its sophistication and allure. For the first time, these warnings begin the critical process of "de-marketing" the product.

\section{Missed opportunities}

Marker words such as "DANGER" or "CAUTION" have the potential to strengthen warnings (as in "DANGER - FLAMMABLE MATERIALS") but markers have not yet been used in conjunction with tobacco warnings (for example, "WARNING - THIS PRODUCT IS HIGHLY
ADDICTIVE"). The exception is the US warnings for smokeless tobacco products, one of which reads "WARNING: This product may cause mouth cancer." Marker words in colours which suggest danger or caution (such as red or yellow) could have strengthened the Canadian warning system.

The warnings also could have benefited by the increased use of upper case lettering. Although readability improves with lower case letters for lengthy messages, short warning messages may have been strengthened with capital letters (for example, "CIGARETTES ARE ADDICTIVE").

Because Canadian packaging must be bilingual, we do not have the luxury of using the reverse face of a package for a more detailed risk message - as the new Australian warning system allows. The reverse side is usually reserved for information in the second language. Therefore, Canadian health agencies have pressed for a detailed warning on the interior of the package, or in the form of an insert.

More detailed messages, if well done, could be a valuable addition to any warning system. Inserts could expand on exterior package warnings, address new risk messages or target specific groups. Existing smokers and potential starters may understand that tobacco causes lung cancer, for example, but few understand that lung cancer is almost always a death warrant. To move closer to "informed consent" between the buyer and the seller of tobacco products, warnings must explain both the nature of the risk and the magnitude of that danger. The absence of more detailed warnings either on, attached to, or in, tobacco packages will almost certainly limit the effectiveness of any warning system.

There are close to two billion cigarette packages sold every year in Canada. Because of the number of packs manufactured plus the frequency with which plates for inserts could be changed, governments could force the rotation of an almost unlimited number of perfectly targeted detailed warnings in cigarette packages. In fact, inserts offer governments the opportunity to produce some of the most effective health education campaigns ever created, at no cost to taxpayers.

Would inserts simply be ignored as the industry has suggested ? Of course - if they are poorly designed. Any block to effectiveness, however, is not linked to a basic weakness in the medium or to a reluctance to learn on the $\mathscr{D}$ part of the user. Any block is more likely to be due to the unwillingness of governments to take the shackles off creative people so that they might design inserts that would demand to be read.

If commercial advertisers were given the opportunity to put their message in a cigarette package, would they turn down the opportunity because they could not draft messages of sufficient interest to entice the smoker to read? Of course not. Warning inserts headed "WARNING - GANGRENE" or "WARNING IMPOTENCE" are just two subjects that would attract interest. Needless to say, if the smoker 3 몸.$$
\text { . }
$$ 
failed to read the message, the smoker's spouse or children might do so.

Precedents for package warning inserts are common for many drugs which are far less harmful than tobacco that are sold over the counter. It is both ironic and tragic, for example, that a nicotine gum product used for smoking cessation is sold with an insert warning of the transfer of nicotine dependence whereas the cigarette that created the original problem is sold with no such warning.

Unfortunately, Canadian legislators and health bureaucrats let the package insert reform slip through their hands. Effective package inserts and exterior package warnings combined with the plain package reform ${ }^{7}$ would take us a long way toward "informed consent". To determine how difficult it might be to achieve an effective warning system, including plain packaging, it may be useful to examine what was involved in securing the tobacco warning system now in place in Canada.

\section{The fight for improved warnings}

The start of the campaign for Canada's current warnings began immediately after passage of the Tobacco Products Control Act (TPCA) in June 1988. In July 1988, a letter was sent to the tobacco manufacturers notifying them of the intention of the federal health department (Health Canada) to enact a strong warning system, including a landmark addiction warning, a warning about ETS, and package insert warnings. Health Canada did not share the letter with the health community.

A federal election campaign was called shortly thereafter and Health Minister Jake Epp was heavily involved in efforts to support the Government's election. In the Minister's absence, tobacco lobbyist William Neville went to work. Mr Neville was a personal friend of Prime Minister Brian Mulroney and a senior strategist in the Prime Minister's re-election campaign. If he did not walk directly from the Prime Minister's office to negotiations with health bureaucrats, it is fair to say that he travelled that path in a figurative sense. When the regulations and the new warnings were announced in December 1988, most of the significant gains in the proposed warning system had been stripped away. Gone were the addiction warning, the ETS warning and the package inserts. Because health agencies had not been aware of the initial proposals, they were unaware of what had been lost in the previous four months.

Soon after, the Non-Smokers' Rights Association (NSRA) started working to improve the warnings. The NSRA was given a huge assist when, using the Access to Information Act, the NSRA obtained documentation that revealed the extent of the industry's lobbying to emasculate the warnings initially proposed. The NSRA's release of the information triggered an angry response in the national media. By that time, a new Minister of Health, the Honourable Perrin Beatty, was in charge. Although he was not responsible for the health portfolio at the time of the industry lobbying, he took steps to correct the ineffective warnings. Mr Beatty, a former Minister of Defence, said that the industry was well positioned to teach the Defence Department a few lessons in "camouflage". The warnings were extremely well concealed in the package colours and design.

The initiative for the new warnings did not originate within the government bureaucracy. Tobacco control reforms seldom do. The NSRA took the initiative to design new warnings and to produce package mock-ups. When the bureaucracy failed to press for effective warnings, the Minister moved forward with the NSRA proposals. The NSRA asked for six major reforms. When the Minister announced his intentions in January 1990, all six NSRA recommendations were accepted. (In fairness, it should not surprise when only a few civil servants show creative leadership on tobacco control. Creative action does not always emerge from the not-for-profit health community either.)

After the announcement, the warnings ran into a three-year stall created by litigation, which had begun late in 1988 . At the time, the tobacco industry moved in court to overturn the TPCA on the grounds that it was unconstitutional. The first major impact from the stall occurred later in 1990. The Government put a freeze on the warnings while it waited to receive the lower court's decision on the challenge to the TPCA. When the court ruled in favour of the manufacturers*, the Government lost all will to proceed with the warnings. This occurred even though the court specifically ruled that the TPCA would remain in full force and effect pending the results of the appeal process.

After the trial decision, a message was sent to the NSRA via a senior government official that "the warnings are dead in the water", that the NSRA should "back off", and that continued agitation for the warnings would only annoy the Government. At this point, the

*When the trial dates were announced in December of 1988, Canadian health agencies were shocked to learn that the Department of Justice lawyers assigned to defend Canada's landmark tobacco legislation were all smokers. Moreover, the outside legal counsel hired by the Department to be lead counsel in the defence was a smoker with no experience in constitutional law. To complete the picture, the judge was also a smoker and, before his relatively recent appointment to the Bench, had been a partner with a law firm that acted for one of the tobacco manufacturers now before the court.

Why was this a concern? Firstly, it revealed a cavalier attitude by the Government with respect to the defence of the statute. Secondly, one of the central issues in the trial was whether or not the tobacco epidemic presented a pressing national concern for the Federal Government. Because smokers tend to view the risks of tobacco use less seriously than do non-smokers, the smoking behaviour of the principals in this litigation introduced a serious risk of bias into this trial and a threat to the perception of fairness. Therefore, the NSRA was not entirely surprised by the lower court decision. 
NSRA sent a strong message back through similar channels. The message was blunt: it was a political decision, not a legal rationale, that led to the direction to "back off", and it would be a political decision that would force the reversal of the decision not to proceed with the warnings. The NSRA, which receives substantial funding from the Federal Government, decided not to "back off".

Then began a lengthy 18- to 24-month battle for the warnings in which the Canadian Council on Smoking and Health (CCSH), the Heart and Stroke Foundation of Canada (HSFC), the Canadian Cancer Society (CCS), the Lung Association, and Physicians for a Smoke-free Canada (PSC) all contributed to an impressive team effort. When Department of Justice lawyers argued against proceeding with the reforms, the NSRA and the CCS countered with legal opinions which argued that there were no legal obstacles to proceeding. When word arrived that the Federal Cabinet was giving a higher priority to the fear of a loss of jobs in the tobacco industry than to public health, the NSRA organised a panel of prestigious economists to examine the role of the tobacco industry in the Canadian economy. The 44-page report that followed, The false dilemma, destroyed the industry's claim of being major players in the economy and gave the Government the economic rationale to proceed with the warnings.

The report concludes:

the tobacco control programme either had no net negative impact on employment or actually increased employment in the Canadian economy. In the 1980s the choice of "lives or jobs" was a false dilemma. Saving lives did not lower total employment. Indeed, the fight to save lives may even have created more jobs than it cost. ${ }^{8}$

Still the Government hesitated, revealing that, when legal opinions and sound economics all point in the direction of the public health option and a decision is still stalled, it is political will that must be given a kick-start. At this point, the NSRA combined with the HSFC to produce the hardest hitting advocacy campaign in the history of Canadian public health. Working through the National Campaign for Action on Tobacco (NCAT), the presidents of Canada's major health agencies and medical societies sent a letter to every household in every constituency of every minister who would be making the decision about whether or not to proceed with the warnings. Fourteen different versions of the letter were prepared. Each was tailored to the constituency and minister involved. In all, NCAT wrote to more than one million Canadians. To launch the campaign, full-page advertisements were published in the Ottawa Citizen and Le Devoir, leading English and French language newspapers.

Well before this time, the Honourable Benoît Bouchard, in turn, had replaced Mr Beatty as Minister of Health. In the spring of 1993, armed with legal opinions, economic studies, and political support, Minister Bouchard and his staff pressed hard for the new warnings. They were finally approved by Cabinet in
August 1993. After all of the political tradeoffs were made, however, the industry was given 13 months to ensure that the warnings were on all packages manufactured or imported as of September 1994.

\section{Manufacturers go to court - again}

The struggle did not end there. In the fall of 1993, the manufacturers attempted to block the warnings in the Supreme Court of Canada. By this time, the Quebec Court of Appeal had reversed the lower court decision and declared the TPCA valid. Nevertheless, the manufacturers argued that the warnings should be delayed until the Supreme Court had reached its decision on the larger issue, the constitutionality of the TPCA. Given the importance of the warnings and the investment in their enactment, national health organisations were not prepared to leave the defence of the warnings to the Department of Justice. They sought and obtained intervenor status in the Supreme Court, largely to send a message to the Court that the health community considered the warnings to be critical to public health. The health agencies recognised the importance of being in the race until the race was over. The Court finally gave unanimous approval for the warnings in February 1994.

\section{Lessons from the front}

The struggle for the warnings was instructive in a number of respects. Firstly, throughout the Government's negotiations with the industry over implementation of the warnings, the manufacturers argued that it would take a minimum of one year to effect the changes in the packaging. Yet the manufacturers stalled for the first several months of the requested implementation period while they waited for a decision from the Court related to the attempt to delay the warnings. They also used a significant portion of the one-year implementation period, not to change their rotogravure printing system (as they had claimed earlier $\mathrm{O}$ that they would need to do), but to do research on package designs, perhaps to try to minimise the impact of the new messages on packaging. N From this experience, we suspect that the manufacturers can make package changes in about a third of the time demanded of the Federal Government.

The manufacturers surely confirmed this conclusion when, in the Supreme Court, they argued that they would introduce all of the desired language changes in the warnings within three months provided that the Court $\mathbb{8}$ would allow the manufacturers to keep the $\mathbb{D}$ warnings at the bottom of the package and in the colours of the packaging. The lesson seems obvious. The manufacturers know that package position and the black and white format of the warnings are a larger threat to sales than the language of the new messages

Secondly, it is instructive that, when faced with being forced to acknowledge that their products are addictive and that ETS causes fatal disease, the manufacturers chose not to 
litigate. They chose not to have the Supreme Court of Canada, the highest court in a respected jurisdiction, put to rest their scientific position that "the jury is still out", that there is a scientific controversy about tobacco addiction or the effects of ETS on nonsmokers.

Thirdly, the industry argued forcefully for the right to attribute the warning to the Government. The focus on attribution in light of the companies passing over other seemingly more important issues suggests that attribution may be a larger block to effective warnings than envisioned earlier.

\section{Effectiveness of the warnings}

Like many tobacco control measures, the effectiveness of the new warnings may be difficult to measure. They entered the market in the same year that Canada experienced severe tobacco tax rollbacks which cut the price of tobacco by almost half in many provinces. Clearly the price cuts would cause a huge market expansion. The most that could be hoped for is that the new warnings would decrease the negative impact of the price reductions. It is obviously difficult, if not impossible, to measure the independent effects of various factors in the market when they occur simultaneously.

We do have anecdotal evidence that the warnings have been noticed. Firstly, in the transition period when both the old and new packaging was on the store shelves simultaneously, many store clerks reported that the packages with the new warnings were often handed back and the old packaging requested. Not all smokers have welcomed the new frankness about risks. The position taken earlier by the Federal Government has been that warnings and health promotion material must not upset smokers, that they must be comfortable with any message. The NSRA position has been that an effective warning system must first of all tell the truth. If that is discomforting to smokers, so be it. A reluctance to accept reality about risks is not sufficient cause to weaken warning systems. A certain degree of discomfort may be associated with creating a new reality about the risks inherent in tobacco use.

In addition, a number of companies have started producing stickers that can cover the warnings on our cigarette packages. The alternative messages on the stickers are sometimes rebellious, frequently an attempt at humour. Even though the stickers may be a temporary act of defiance, they are evidence that the federal warnings are being noticed by consumers. Why else would smokers go to time and expense to cover these messages?

1 Chapman S. Industry down again down under. Tobacco Control 1995; $4: 17$.

2 Tobacco products control regulations, PC 1989-787, 4 May 1989, PC 1993-1542, 21 July 1993, PC 1993-2161, 22 December 1993.

3 Kaiserman MJ. The effectiveness of health warning messages. Tobacco Control 1993; 2: 267-9.

4 Tobacco Products Control Act, RSC C20, 1988.

5 RJ Reynolds Tobacco Company (advertisement). If we said it, you might not believe it. Wall Street $\mathcal{F} 1994$ May 26:

6 Naett C, Howie C. The labelling of tobacco products in the European Union. Brussels: European Bureau for Action European Union. Brussels: European B
on Smoking Prevention, 1993: 11-12.

7 Cunningham $\mathrm{R}$, Kyle $\mathrm{K}$. The case for plain packaging Tobacco Control 1995; $4: 80-6$.
Cunningham $R$, Kyle K. The case

8 Allen RC. The false dilemma: the impact of tobacco control policies on employment in Canada. Ottawa: National Campaign for Action on Tobacco, 1993: 21.

\section{$\frac{\text { HEALTH HAZARD }}{\text { SECOND-HAND SMOKE POLLUTION }}$ Will it really harm my family?}

Yes. Second-hand tobacco smoke is the smoke from the burning tip of the cigarette combined with the smoke the smoker exhales. It can harm others around you. It can cause disease including deadly lung cancer in non-smokers.

Children of parents who smoke suffer from more chest infections and asthma than children of non-smokers.

Second-hand smoke is a significant health hazard for the 1 in 5 adults who already have heart, lung, and allergic diseases. Smoking out-of-doors is one answer. Stopping smoking is another. For help, call a local health agency.

Examples of proposed detailed warnings for insertion in Canadian tobacco packages. The versions shown here are reduced in size from that which would be used in actual packs (about $87 \times 90 \mathrm{~mm}$ ). 